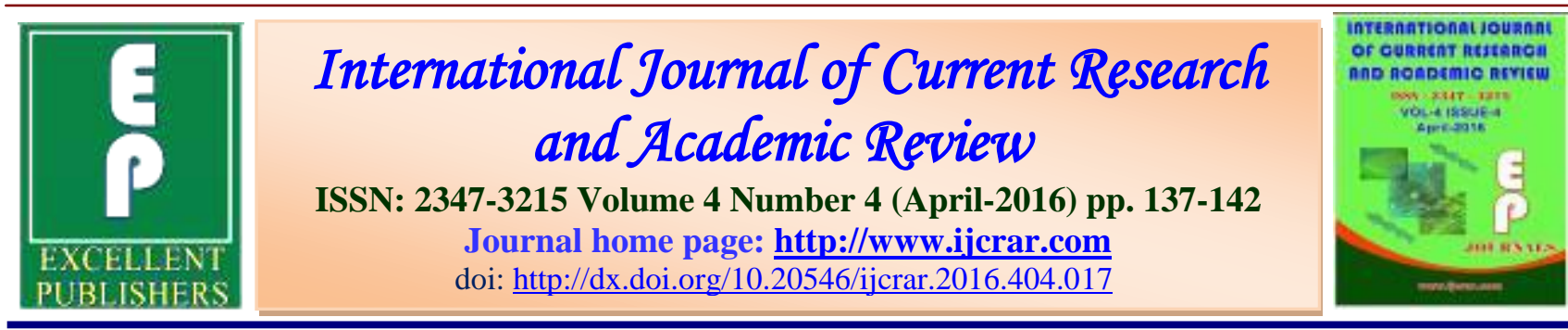

\title{
Good Agriculture and Cultivation Practices in Medicinal Plants; Monitoring on Vermicompost on Some High Demand Prioritized Medicinal Plants used in ISM \& $\mathbf{H}$
}

\section{Shweta Yadav*}

Department of Zoology, Dr H S Gour Vishwavidalaya (A Central University), Sagar-470003, MP, India

*Corresponding author

\begin{tabular}{l|l} 
KEYWORDS & A B S T R A C T
\end{tabular}

Medicinal Plants

Following WHO emphasis to grow medicinal plants organically and avoid use of chemicals, pesticides, NMPB, New Delhi had sanctioned this project to author which had expertise in vermitechnology to take-up organic cultivation of medicinal plants and provided technology to farmers. The study was focused to identify the medicinal crops that could be suggested to farmers for cultivation so as to ensure their marketing. The personal interaction with the leading manufacturers of Ayurvedic/Unani drugs under this study has reassured us that they are quite responsive to use authentic genuine raw materials obtained from the cultivation source and through organic farming so as to maintain quality standards of their products, even, if, this is at a comparatively higher cost. Farmers were educated (2006-2009) and trained in cultivation practices of medicinal crops particularly the high demand prioritized species, besides some traditional crops to get higher income returns. This move was likely to generate employment opportunities in rural area and improve the economy of rural masses, particularly the weaker sections of society of study area.

\section{Introduction}

In recent years, there has been overwhelming response to the organic produces in the world which is growing @ $20 \%$ per annum. In medicinal and herbal sectors this is absolutely necessary as all the major European, Japanese and North American buyers are demanding chemical free raw materials and products (Yadav and Singh, 2014). Therefore, organic cultivation of medicinal plants is the need of the hour. Hence, national and international level of efforts and research are needed to facilitate the successful adoption of organic cultivation and production of medicinal and aromatic plants farmers and collectors. The present study (2006-2009) was focused to organize specific training programmes for a group of selected farmers to trained on Good 
Agricultural \& Collection Practices (GACP) of medicinal crops.

\section{Materials and Methods}

Vermicomposting units was set-up in study area(Western UP, District Aligarh) by promoting utilization of organic waste to produce 5-6 MT compost every year from each unit. To make available sufficient quantity of organic manure for application in the upcoming medicinal crops cultivated by farmers of Western UP. Use of vermicompost was monitored on Ashwangandha (Withania somnifera), Kawanch (Mucuna prurita), Kalmegh (Andrographis paniculata), Senna (Cassia augustifolia) and Kanta karanj (Caesalpinia crista) in farmers' fields. Farmers were trained to set vermicompost units in their lands. Technical and managerial back-up was also provided to the unit and provide market assistance during study period (2006-2009).

\section{Results and Discussion}

Some 500 farmers have been provided technical guidance in the production of medicinal plants with organic manure in study area. This was made by setting-up 42 vermicompost units together with providing information on agro-techniques for cultivation of medicinal crops at the farmer's land. Eight "Demonstration Plots" on medicinal plants namely Ashwgandha, Sanai, and Kalmegh were set-up in three development blocks of Aligarh and Hathras districts in western U.P. to educate the farmers. Certified Seed and vermicompost were provided through the project to farmers for live-demonstration of medicinal crops at the land of beneficiaries. A Herbal Agro Development Gramudyog Society, Aligarh. (U.P) was developed and the farmers were provided planting material and technical expertise etc for cultivation of medicinal crops. To keep record of day-to-day activity of cultivation of medicinal crops and preparation of vermicompost by farmers, a diary has been devised. Since the programme on farmers' meets on "Awareness Training and Cultivation of medicinal plants and Vermitechnology" were in public interest, all events have been given wide media coverage. Under this project study, some $161 \mathrm{~kg}$ seeds of selected high demand prioritized medicinal crops suitable for cultivation in the agro-climatic conditions of Western UP have been distributed to farmers to take-up field scale cultivation. A preliminary survey of selected medicinal plants (raw drugs) used by 37 Aryurvedic \& Unani manufacturers of Aligarh \& Hathras districts of Western UP was conducted and reported considerable consumption of medicinal plants in this region as below:

\section{Sl. No. Botanical Name}

1. Andrographis paniculata

2. Withani somnifera (1.)

3. Mucuna prurita Hook

4. $\quad$ Aloe barbadenisis (L.)

5. Cassia augustifolia Vahl

6. Others

\section{Common name}

Kalmegh

Ashwagandha

Konch

Gheekwar

Senna/Sanai
Quantity used (annually)

$1032 \mathrm{~kg}$ (Burm f.) wall ex Nees

$1090 \mathrm{~kg}$ Dunal

$282 \mathrm{~kg}$

$740 \mathrm{~kg}$ Burm. f.

$1124 \mathrm{~kg}$

$1725 \mathrm{~kg}$ 
Figure.1 Inauguration of Biofair 2008: Sitting on the dice is Shri B.S. Sajwan, Chief Executive Officer, National Medicinal Plants Board, New Delhi (second from right)

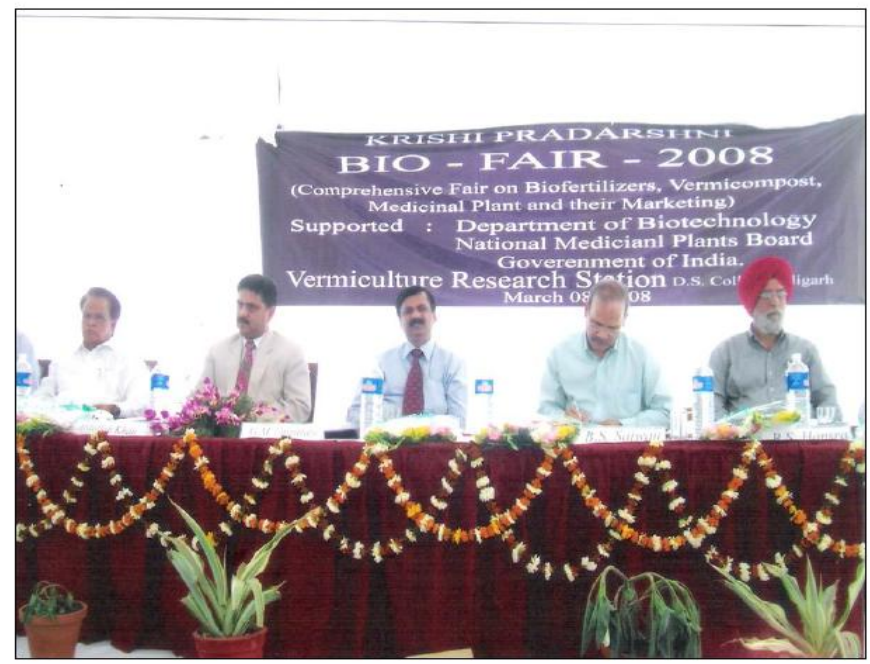

Figure.2 Shri B.S. Sajwan, CEO, NMPB, visiting a stall and discussing about use of biofertilizers in medicinal crops on 8 March, 2008

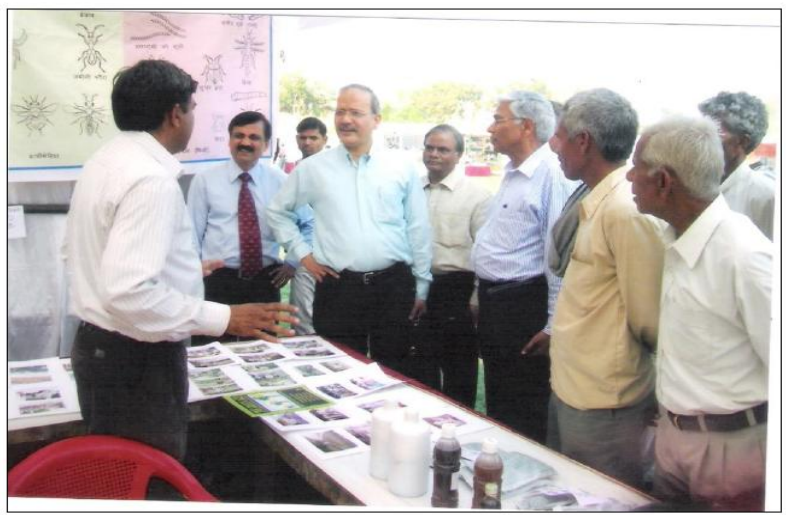

Figure.3 Participation of project in Aligarh agricultural and industrial exhibition 2008: Note display of medicinal plants and the visitors

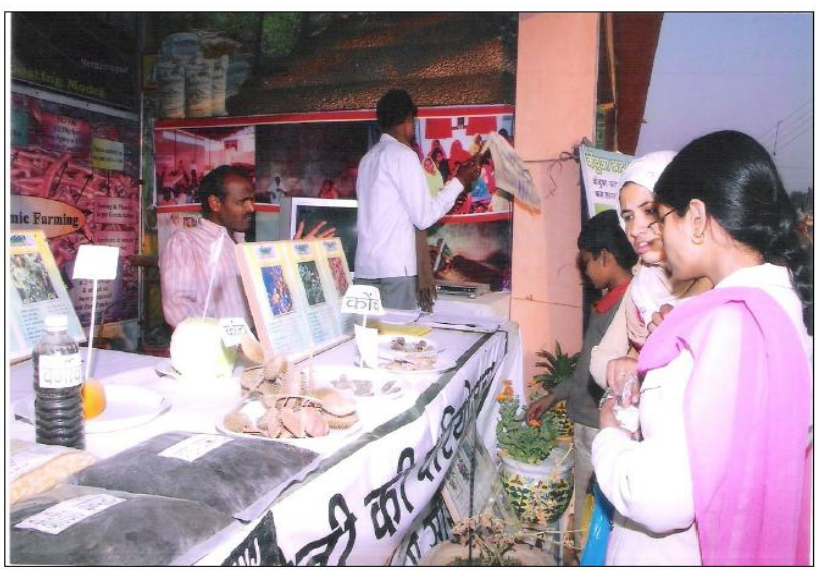


Figure.4 A view of field scale cultivation of Kalmegh under project by a farmer in a village in district Aligarh during 2007-2008

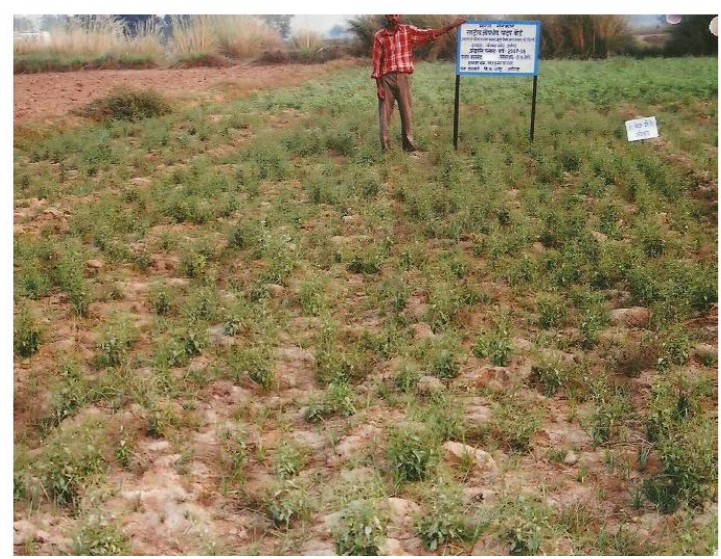

Figure.5 A view of demonstration of vermitechnology at the Biofair-2008: Shri B.S. Sajwan, CEO, looks on the process. Dr. Shweta, PI explaining a point to him.

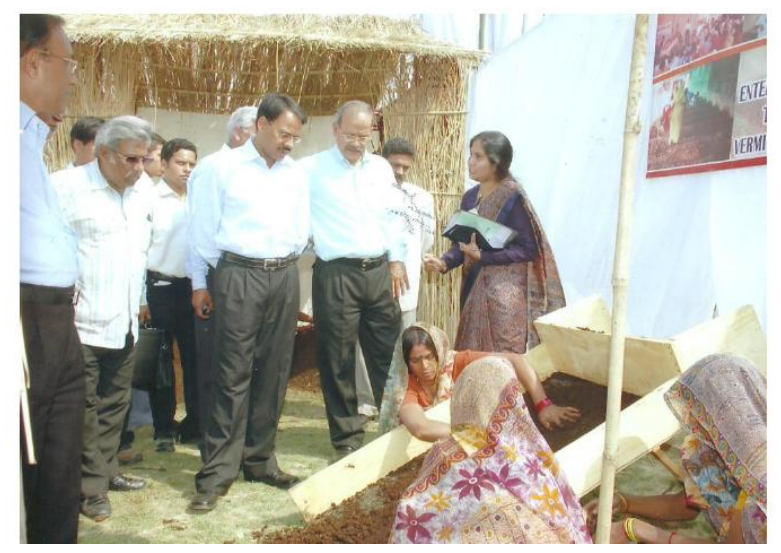

Figure.6 Shri R.P. Singh, a manufacturer of herbal drugs, showing a plants of Giloy (Tinospora cordifolia) and Gheekwar (Aloe vera) during a farmers meet on 26.07.2009 organized by the project at Vermiculture Research Station, D.S. College, Aligarh

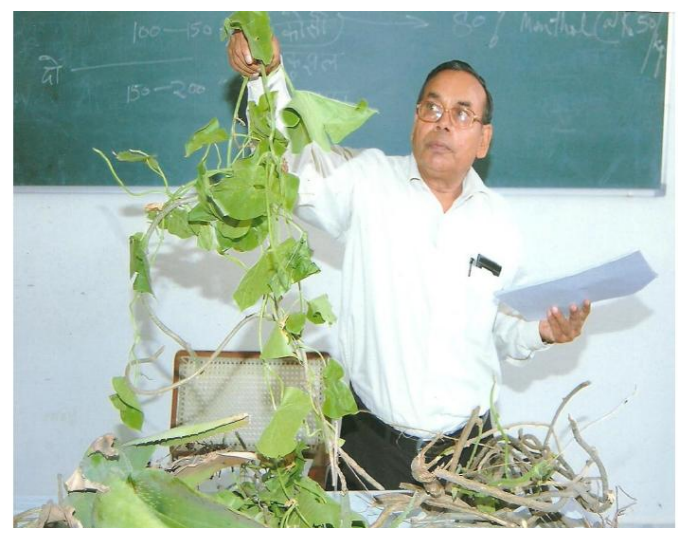


Figure.7 A view of inaugural session of training programme on Mentha cultivation organized under project on 26.07.2009 at the Vermiculture Research Station, D.S. College, Aligarh

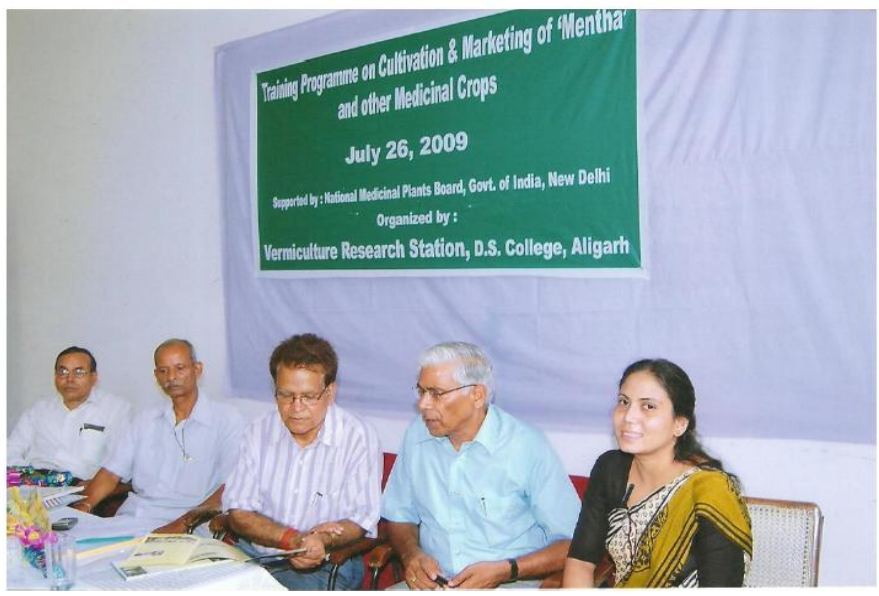

Figure.8 A view of experimentation on Ashwagandha and Kalmegh under controlled conditions at the project site at Vermiculture Research Station, D.S. College, Aligarh, during 2006-2007

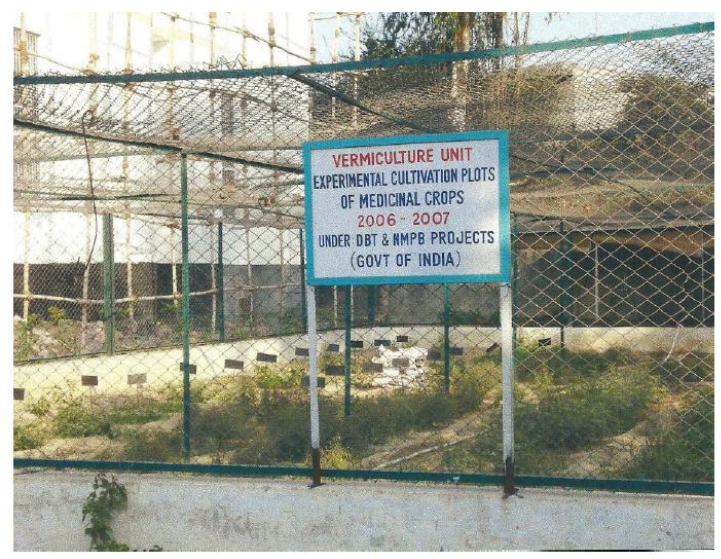

Figure.9 A view of trial plot of Kalmegh at vill. Andala, Block Hassain, Distt. Aligarh, during 2007-2008

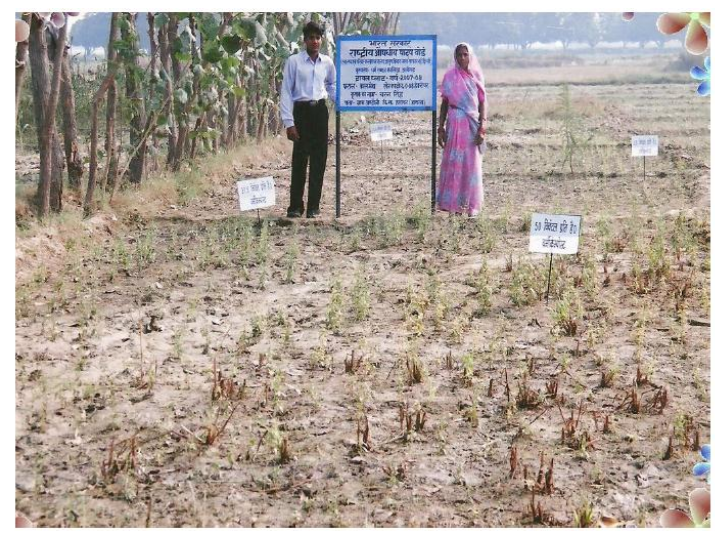


Figure.10 A view of farmers stall in Biofair-2006: Note display of Jatropha plants.

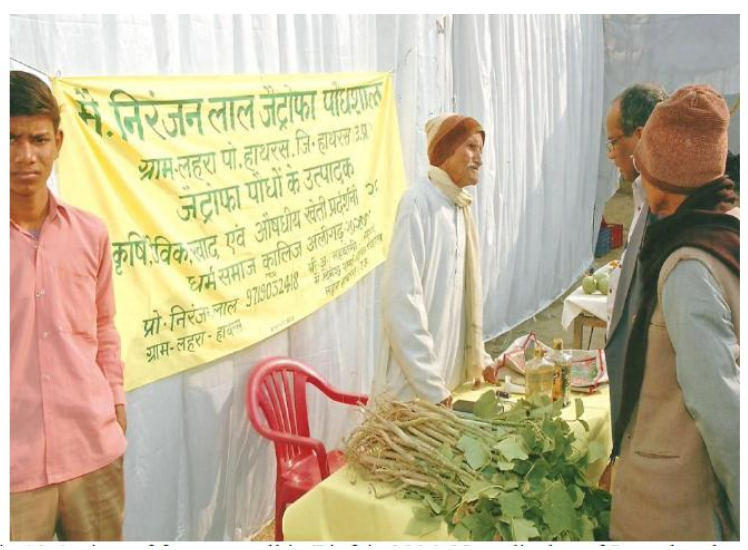

\section{Conclusions}

It can be concluded vermicompost is a prerequisite for organic cultivation of medicinal crops. The study to assess the demand of raw drugs by 37 ISM pharmacies of Aligarh and Hathras districts was conducted with a view to set priorities of medicinal crops for cultivation by the farmers of this region. The study indicated that some $5993 \mathrm{~kg}$ raw drugs are currently consumed in this region for preparation ISM medicines. However, sustained efforts were essential to provide technical and managerial back-up to farmers to continue with the production of vermicompost for application in the medicinal crops cultivated by them.

\section{Acknowledgement}

We acknowledge the financial support of National Medicinal Plants Board (Ministry of Health \& Family Welfare Department of
AYUSH) Government of India New Delhi, to carry out this study.

\section{References}

Yadav Shweta, Singh, V.K. 2009. Good Agriculture and Cultivation Practices in Medicinal plants; monitoring on vermicompost on some high demand prioritized medicinal plants used in ISM \& H. Report submitted to National Medicinal Plants Board (Ministry of Health \& Family Welfare Department of AYUSH) Government of India, New Delhi Project No.: GO/UP-01/2007

Yadav Shweta, Singh, V.K. 2014. Vermitechnology: Rebuilding of Sustainable Livelihoods. Nova Science Publisher, Inc: 400 Oser, Ave, Suite 1600: Hauppauge, New York 117883619 USA, ISBN: 978-1-6317-943-3.

Yadav Shweta, 2014. Empowerment of Weaker Section of Society through Vermitechnology. LAP Lambert Academic Publishing, Germany.

\section{How to cite this article:}

Shweta Yadav. 2016. Good Agriculture and Cultivation Practices in Medicinal Plants; Monitoring on Vermicompost on Some High Demand Prioritized Medicinal Plants used in ISM \& H.Int.J.Curr.Res.Aca.Rev.4(4): 137-142. doi: http://dx.doi.org/10.20546/ijcrar.2016.404.017 